\title{
Theoretical Mechanism Study on the Reaction of FOO Radical with NO
}

\author{
ShunLi Ou Yang, ${ }^{1}$ NanNan Wu, ${ }^{1,2}$ JingYao Liu, ${ }^{3}$ and XiangGang Han ${ }^{2}$ \\ ${ }^{1}$ Key Laboratory of Integrated Exploitation of Bayan Obo Multi-Metal Resources, Inner Mongolia University of Science \& Technology, \\ Baotou 014010, China \\ ${ }^{2}$ School of Mathematics, Physics and Biological Engineering, Inner Mongolia University of Science \& Technology, \\ Baotou 014010, China \\ ${ }^{3}$ Institute of Theoretical Chemistry, State Key Laboratory of Theoretical and Computational Chemistry, Jilin University, \\ Changchun 130023, China
}

Correspondence should be addressed to NanNan Wu; woshinannan04@imust.cn

Received 15 September 2015; Revised 20 December 2015; Accepted 22 December 2015

Academic Editor: Teodorico C. Ramalho

Copyright (C) 2016 ShunLi Ou Yang et al. This is an open access article distributed under the Creative Commons Attribution License, which permits unrestricted use, distribution, and reproduction in any medium, provided the original work is properly cited.

The mechanism for the reaction of radical FOO with NO was investigated theoretically. The electronic structure information for the singlet potential energy surfaces (PES) was obtained at the MP2/6-311+G(2df) level of theory, and the single-point energies were refined by the $\operatorname{CCSD}(\mathrm{T}) / 6-311+\mathrm{G}(2 \mathrm{df})$ level. The rate constants as well as the pressure and temperature dependence of various product channels for the reaction are predicted. The calculated results show that starting from the energy-rich intermediate $\mathrm{FOONO}_{\text {tp }}$ (IM1), at room temperature $298 \mathrm{~K}$ and at 1 Torr, FNO is the exclusive product which is consistent with the experimental results. The present results will be useful to gain a deep insight into the reaction mechanism of FOO + NO reaction.

\section{Introduction}

Free radical FOO is generated in the collision of fluorine and oxygen system at low temperature (e.g., photolysis and radiolysis) [1]. It is one of the most important free radicals containing fluorine in atmosphere and has considerable high thermodynamic stability. Similar to free radical ClOO, FOO also has a very weak fluorine-oxygen bond (F-O) with dissociation energy smaller than $11.7 \mathrm{kcal} \cdot \mathrm{mol}^{-1}$ [2]. Generally speaking, FOO acts as a pure fluorine atom in chemical reactions instead of a free radical. In the atmosphere, with high oxygen concentration and quick fluorine-oxygen reaction, so $\mathrm{F}+\mathrm{O}_{2}+\mathrm{M} \rightarrow \mathrm{FOO}+\mathrm{M}$ reaction is the main transfer mechanism of fluorine atom. FOO radical can also be involved in the circulation of ozone depletion [3-7]. One of such circulations includes the reaction of FO, FOO, and $\mathrm{O}_{3}$ :

$$
\begin{gathered}
\mathrm{FO}+\mathrm{O}_{3} \longrightarrow \mathrm{FOO}+\mathrm{O}_{2} \\
\mathrm{FOO}+\mathrm{O}_{3} \longrightarrow \mathrm{FO}+2 \mathrm{O}_{2}
\end{gathered}
$$

$$
\mathrm{O}_{3}+\mathrm{O}_{3} \longrightarrow 3 \mathrm{O}_{2}
$$

Effect of this circulation on ozone layer depends on dynamics of $\mathrm{FO}$ and $\mathrm{FOO}$ reactions with $\mathrm{O}_{3}$. Dynamics of these two reactions are determined by elimination reaction rate of FO and FOO by other chemical elements, such as $\mathrm{NO}, \mathrm{NO}_{2}$, and hydrocarbons. Therefore, $\mathrm{FOO}+\mathrm{NO}$ reaction, an important connector between $\mathrm{FO}_{x}$ and $\mathrm{NO}_{x}$ free radical series, plays an important role in eliminating atmospheric pollution and reducing ozone depletion.

Two experimental groups studied the FOO + NO reaction. They detected and discussed two available reaction channels:

$$
\begin{aligned}
& \mathrm{FOO}+\mathrm{NO} \longrightarrow \mathrm{FNO}+\mathrm{O}_{2} \\
& \mathrm{FOO}+\mathrm{NO} \longrightarrow \mathrm{FO}+\mathrm{NO}_{2}
\end{aligned}
$$

In 1994, Sehested et al. [5] tested the idea that the reaction rate constant under $298 \mathrm{~K}$ is $k(\mathrm{FOO}+\mathrm{NO})=(1.47 \pm 0.8)$ $\times 10^{-12} \mathrm{~cm}^{3}$ molecule $\mathrm{s}^{-1}$ and determined that the yield of FNO in main reaction channel (4) is $100 \pm 14 \%$. Subsequently, 
Li et al. [8] tested the reaction rate constant under 1 Torr and $190 \sim 298 \mathrm{~K}$ and proposed the Arrhenius expression of two parameters of the $\mathrm{FOO}+\mathrm{NO}$ reaction: $k(\mathrm{FOO}+\mathrm{NO})$ $=(7.5 \pm 0.5) \times 10^{-12} \exp [(-688 \pm 377) / T] \mathrm{cm}^{3}$ molecule $^{-1} \mathrm{~s}^{-1}$. They concluded that reaction channel (4) is the main reaction channel and branching ratio of $\mathrm{NO}_{2}$ in reaction channel (5) is smaller than 0.03 . Although data of these two groups agree well with each other, no experimental research on the reaction mechanism, other possible products, and reaction rate constants and branching ratios of $\mathrm{FOO}+\mathrm{NO}$ reaction under wider temperature and pressure ranges has been reported yet. According to our knowledge, Dibble and Francisco [9] believed that $\mathrm{FNO}_{3}$ system such as FOO + $\mathrm{NO}$ and $\mathrm{FO}+\mathrm{NO}_{2}$ may occur via the intermediate FOONO which is the isomer of fluorine nitrate $\mathrm{FONO}_{2}$ theoretically. Therefore, we guessed that $\mathrm{FOO}+\mathrm{NO}$ reaction may have other unimolecular products within certain temperature and pressure ranges. In addition, Sun et al. [10] carried out a theoretical study on this reaction and its reverse reaction $\mathrm{FO}+\mathrm{NO}_{2}$ at CCSD $(\mathrm{T}) / 6-311+\mathrm{G}(2 \mathrm{~d}) / / \mathrm{B} 3 \mathrm{LYP} / 6-311+\mathrm{G}(2 \mathrm{~d})$ level of theory in 2009. Although they have got relative detailed singlet potential energy surface, they did not calculate the kinetics of the $\mathrm{FOO}+\mathrm{NO}$ reaction. Kinetics information within other temperature and pressure ranges of the reaction is still not clear. Under these circumstances and considering the great significance of this reaction in atmospheric chemistry, a comprehensive theoretical study is thus highly desirable to shed light on the reaction mechanism and kinetics. In the present work, we explored the potential energy surfaces (PES) by performing quantum chemistry calculations and did the kinetic calculations using microcanonical Rice-Ramsperger-Kassel-Marcus (RRKM) unimolecular rate theory [11]. The PES information was obtained at the $\operatorname{CCSD}(\mathrm{T}) / 6-311+\mathrm{G}(2 \mathrm{df}) / / \mathrm{MP} 2 / 6-311+\mathrm{G}(2 \mathrm{df})$ level of the theory, and the reaction rate constants and branching ratios variations of the various product channels were discussed with respect to temperature and pressure.

\section{Calculation Methods}

The geometries of all of the reactants, products, intermediates, and transition states involved in the $\mathrm{FOO}+\mathrm{NO}$ reaction were optimized using the second-order level of closed shell MФller-Plesset MP2 [12] perturbation theory in conjunction with the $6-311+\mathrm{G}(2 \mathrm{df})$ basis set. Frequency calculations were performed at the same level to check whether the obtained species is an equilibrium species (with all real frequencies) or a transition state (with one and only one imaginary frequency). To confirm that the transition states connect designated intermediates, we also performed intrinsic reaction coordinate (IRC) [13-16] calculations at the MP2/6-311+G(2df) level. To obtain more reliable energetic data, single-point energy calculations were performed at the $\operatorname{CCSD}(\mathrm{T}) / 6-311+\mathrm{G}(2 \mathrm{df})$ level using the MP2/6-311+G(2df) optimized geometries of all the species. Unless noted, the $\operatorname{CCSD}(\mathrm{T})$ energies with inclusion of MP2 zero-point vibrational energies (ZPE) are used throughout. All calculations were carried out using the Gaussian 03 program packages [17].
According to the variational transition state and RRKM [11] theories, the kinetic calculations for this multichannel and multiwell reaction were carried out via the MultiWell $2011[18,19]$ program on the basis of the PES obtained above in order to identify the likely mechanism and the branching ratios of various product channels.

\section{Results and Discussion}

3.1. Potential Energy Surface and Reaction Mechanism. The optimized geometries of the reactants, products, intermediates, and transition states for $\mathrm{FOO}+\mathrm{NO}$ reaction are shown in Figure 1, respectively. The schematic profile of the PES is depicted in Figure 2. The total energy of the reactant $\mathrm{R}$ $[\mathrm{FOO}+\mathrm{NO}]$ is set to be zero for reference, and the values in parentheses are relative energies in $\mathrm{kcal} / \mathrm{mol}$ with reference to that of $\mathrm{R}$. The examined reaction can proceed via addition reaction pathway, corresponding to five possible product formation channels. The intermediates are correspondingly numbered IM1-IM3 and the products in these five channels, $\mathrm{FNO}+{ }^{1} \mathrm{O}_{2}$ and $\mathrm{FO}+\mathrm{NO}_{2}$, are located in the same order, $\mathrm{P}_{1}$ and $\mathrm{P}_{2}$, respectively. In addition, there are nine transition states (denoted as TS) and three secondary products $\left(\mathrm{P}_{3}\right.$ $\mathrm{FONO}_{2}, \mathrm{P}_{4} \mathrm{~F}+\mathrm{NO}_{3}$, and $\mathrm{P}_{3}^{\prime}$ ) involved in the singlet PES.

3.1.1. Entrance Channels. It can be seen from Figure 2 that the reaction of FOO radical with $\mathrm{NO}$ radical may proceed via $\mathrm{N}$ atom of the $\mathrm{NO}$ radical attacked on $\mathrm{O}$ atom of the FOO radical, leading to the energy-rich entrance intermediate IM1 $\mathrm{FOONO}_{\mathrm{tp}}(-19.8 \mathrm{kcal} / \mathrm{mol})$ on the singlet PES. Such radical-radical addition process is barrierless. This process makes intermediate IM1 highly activated so that further isomerization or dissociation from it is possible. This is a typical radical-radical reaction mechanism. We should note that IM1 can convert to its cis-form IM2 FOONO $(-19.6 \mathrm{kcal} / \mathrm{mol})$ by the $-\mathrm{NO}$ group rotation transition state $\mathrm{TS}_{\text {IM1-IM2 }}(-14.0 \mathrm{kcal} / \mathrm{mol})$.

3.1.2. Isomerization and Dissociation. There are three dissociation and isomerization pathways starting from IM1 FOONO $_{\text {tp }}$ : (1) 1,3 F-atom transfers and produces $\mathrm{P}_{1} \mathrm{FNO}+$ ${ }^{1} \mathrm{O}_{2}$ (-35.4 kcal $\left./ \mathrm{mol}\right)$ through a four-membered ring transition state $\mathrm{TS}_{\mathrm{IM} 1-\mathrm{P}_{1}}(-2.3 \mathrm{kcal} / \mathrm{mol}) ;(2)$ direct $\mathrm{O}-\mathrm{O}$ bond breaks and produces $\mathrm{P}_{2} \mathrm{FO}+\mathrm{NO}_{2}(-2.6 \mathrm{kcal} / \mathrm{mol})$ through the transition state $\mathrm{TS}_{\mathrm{IM} 1-\mathrm{P}_{2}}(11.3 \mathrm{kcal} / \mathrm{mol})$ or $\mathrm{TS}_{\mathrm{IM} 1-\mathrm{P}_{2}}^{\prime}$ (10.2 kcal $/ \mathrm{mol}) . \mathrm{P}_{2}$ can produce $\mathrm{P}_{3} \mathrm{FONO}_{2}(-39.0 \mathrm{kcal} / \mathrm{mol})$ without energy barrier, which could further transform to $\mathrm{P}_{4} \mathrm{~F}+\mathrm{NO}_{3}(-3.1 \mathrm{kcal} / \mathrm{mol})$ (via loose variational transition state barrierlessly) and $\mathrm{P}_{3}^{\prime}$ (through the transition state $\mathrm{TS}_{\mathrm{P}_{3}-\mathrm{P}_{3}^{\prime}}$ $(-30.8 \mathrm{kcal} / \mathrm{mol}))$; (3) concerted $\mathrm{N}-\mathrm{O}$ and $\mathrm{O}-\mathrm{F}$ bonds break and form IM3 $(-5.7 \mathrm{kcal} / \mathrm{mol})$ which is a complex with loose structure via the transition state $\mathrm{TS}_{\mathrm{IM} 1-\mathrm{IM} 3}(-3.8 \mathrm{kcal} / \mathrm{mol})$. Then, IM3 also can produce $\mathrm{P}_{1}$ through the transition state $\mathrm{TS}_{\text {IM3-P }}(-5.8 \mathrm{kcal} / \mathrm{mol})$ after overcoming a $3.7 \mathrm{kcal} / \mathrm{mol}$ energy barrier. Obviously, since energy of rate-limiting step $\mathrm{TS}_{\text {IM1- } \mathrm{P}_{2}}$ in channel (2) is positive and far higher than those of TS IM1-P $1_{1}$ and TS $\mathrm{IM1}_{\mathrm{IM} 3}$ in channels (1) and (3), channel (2) 


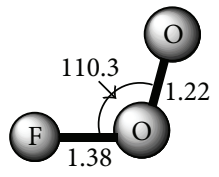

FOO
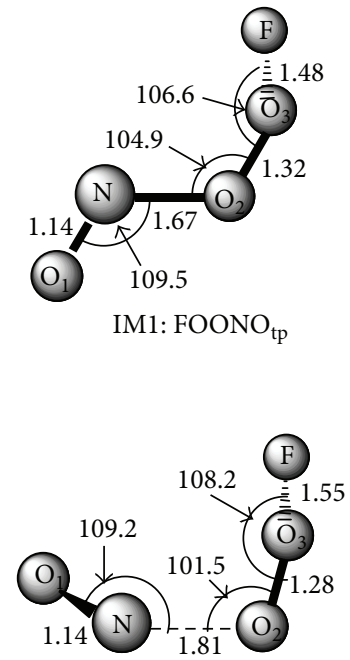

$\mathrm{TS}_{\mathrm{IM} 1-\mathrm{IM} 2}$

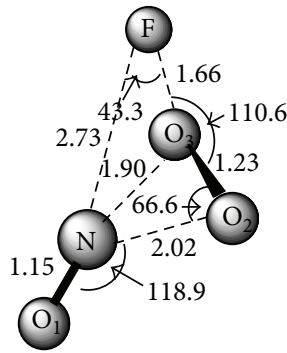

$\mathrm{TS}_{\mathrm{IM} 1-\mathrm{IM} 3}$

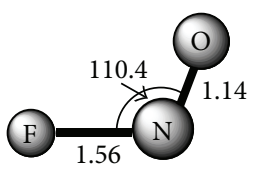

FNO
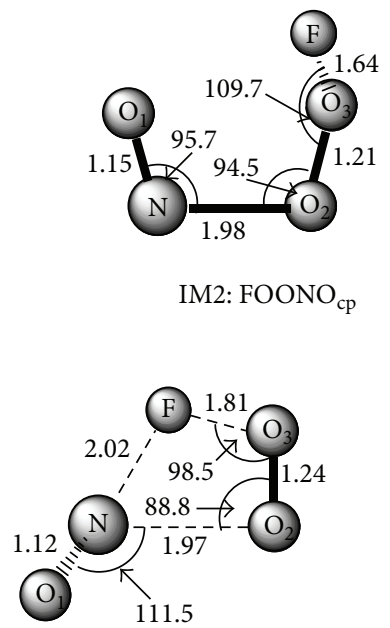

$\mathrm{TS}_{\mathrm{IM} 1-\mathrm{P}_{1}}$
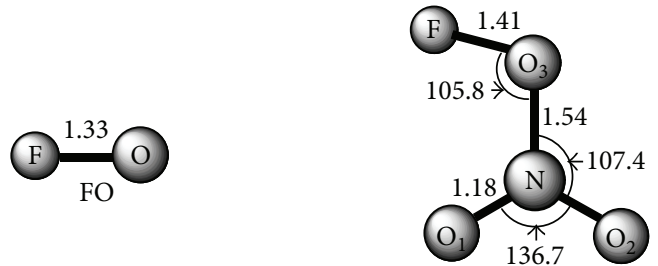

$\mathrm{FONO}_{2}$

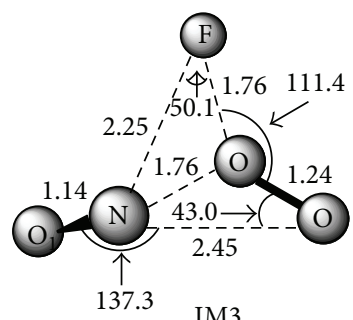

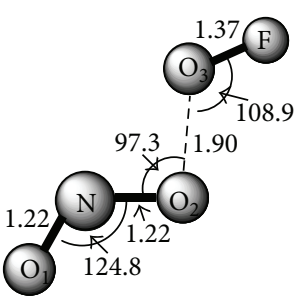

$\mathrm{TS}_{\mathrm{IM} 1-\mathrm{P}_{2}}$

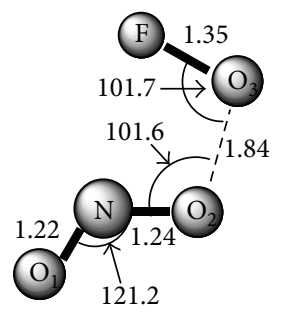

$\mathrm{TS}_{\mathrm{IM} 1-\mathrm{P}_{2}}^{\prime}$

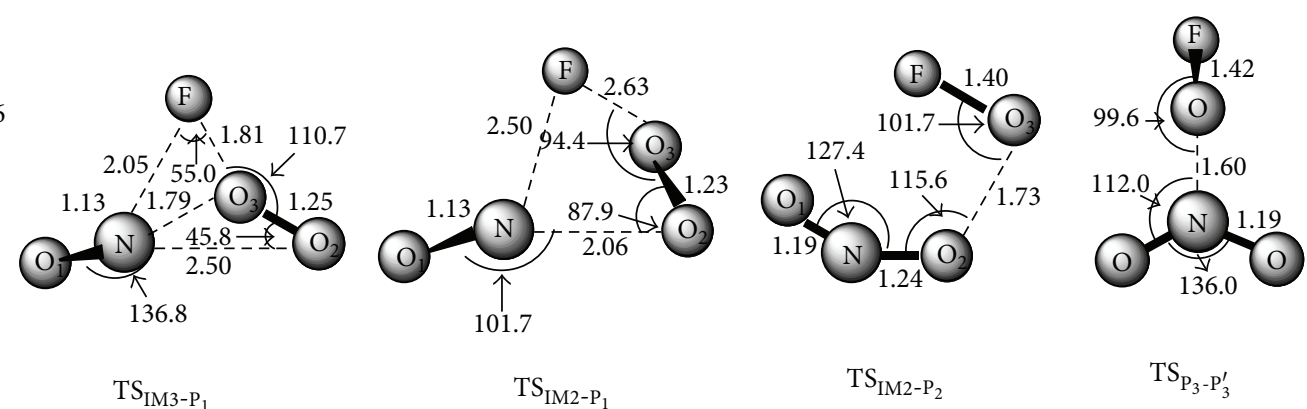

FIGURE 1: MP2/6-311+G(2df) optimized geometries for the reactants, products, intermediates (IM), and the corresponding transition states (TS) of FOO + NO reaction. Bond lengths are in $\AA$ and bond angles are in degree.

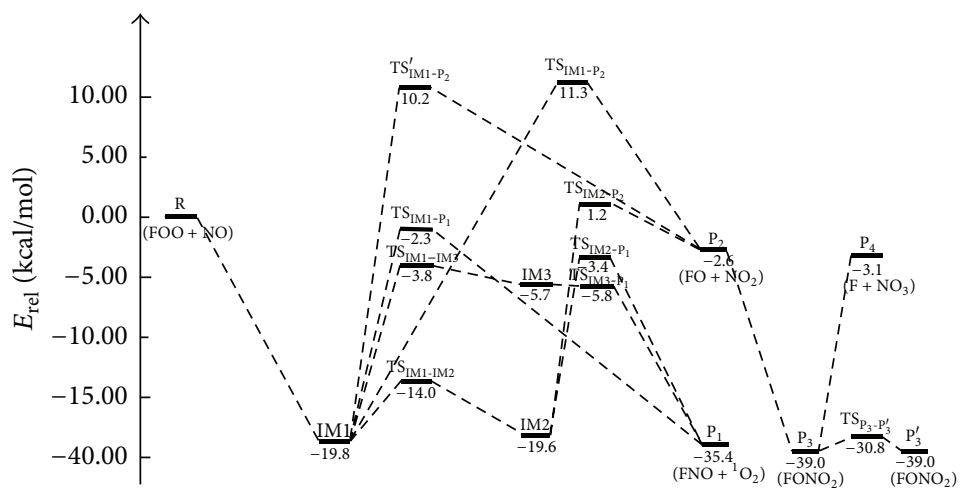

FIGURE 2: Schematic singlet potential energy surface of each product channel for FOO + NO reaction at the CCSD(T)/6-311+G(2df)//MP2/6$311+G(2 d f)+Z P E$ level. 


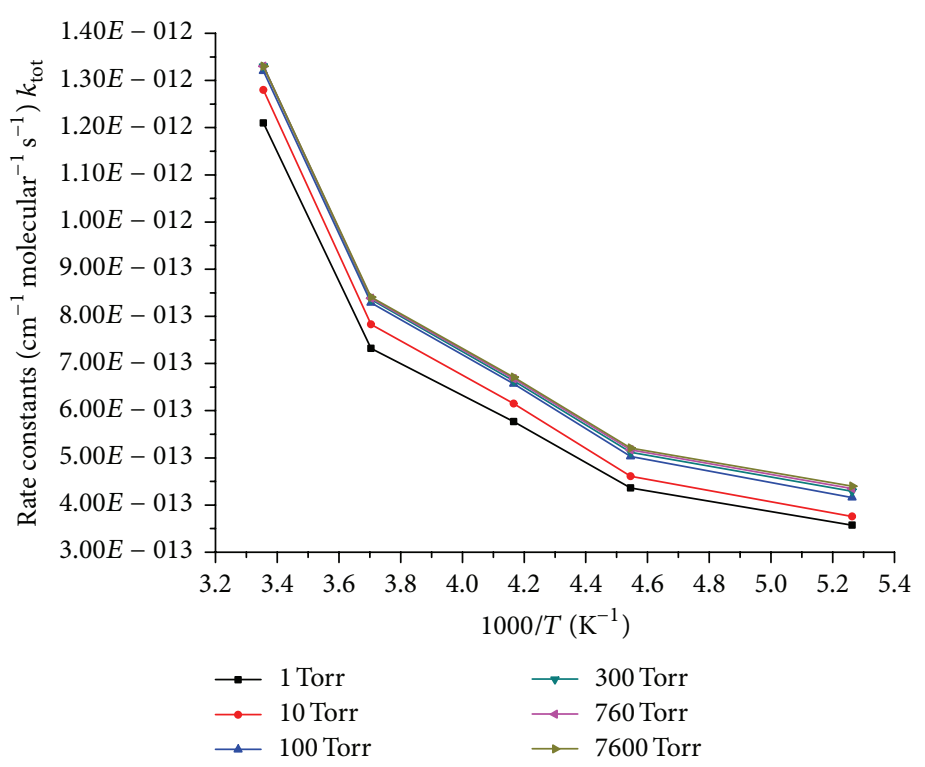

FIGURE 3: The total reaction rate constant $\left(k_{\text {tot }}\right)$ at various pressures of 1, 10, 100, 300, 760, and 7600 Torr in a temperature range of 200-298 K.

could not compete with channels (1) and (3) and is neglected in the following kinetic calculation.

Two dissociation and isomerization reaction channels were determined from IM2 $\mathrm{FOONO}_{\mathrm{cp}}$. Firstly, IM2 could either make 1,3 F-atom transfer via a four-membered ring transition state $\mathrm{TS}_{\text {IM2- }}(-3.4 \mathrm{kcal} / \mathrm{mol})$ to produce $\mathrm{P}_{1}$ or make direct $\mathrm{O}-\mathrm{O}$ bond breakage through the transition state $\mathrm{TS}_{\text {IM2- } \mathrm{P}_{2}}(1.2 \mathrm{kcal} / \mathrm{mol})$ to produce $\mathrm{P}_{2}$. Apparently, the later dissociation channel has to overcome higher energy barriers, which is unavailable in energy. Therefore, it is neglected in the following kinetic calculations.

In summary, the most possible reaction pathways for $\mathrm{FOO}+\mathrm{NO}$ reaction are

$$
\begin{aligned}
\mathrm{R}(\mathrm{FOO}+\mathrm{NO}) & \longrightarrow \mathrm{IM}^{*} \mathrm{FOONO}_{\mathrm{tp}} \\
& \longrightarrow \mathrm{IM} 1 \longrightarrow \mathrm{P}_{1} \mathrm{FNO}+{ }^{1} \mathrm{O}_{2} \\
& \longrightarrow \mathrm{IM} 3 \longrightarrow \mathrm{P}_{1} \mathrm{FNO}+{ }^{1} \mathrm{O}_{2} \\
& \longrightarrow \mathrm{IM} 2 \mathrm{FOONO}_{\mathrm{cp}} \\
& \longrightarrow \mathrm{P}_{1} \mathrm{FNO}+{ }^{1} \mathrm{O}_{2}
\end{aligned}
$$

It is seen that, on the singlet PES, the formations of three intermediates IM1-IM3 and one product fragment $\mathrm{P}_{1}$ are most likely accessible just from the energetic point of view (see Figure 2). Both our and Sun et al.s [10] calculations on the potential energy surface believe that $\mathrm{P}_{1}$ is the major dissociation product of $\mathrm{FOO}+\mathrm{NO}$ reaction. However, the reaction mechanism we predicted is different from that of Sun et al. [10]. In this paper, $\mathrm{P}_{1}$ has more generation channels that have to overcome smaller energy barriers. Moreover, it is difficult to determine which are the probable reaction channels and feasible products at different temperatures and pressures solely on the basis of energies. To provide the product distributions and the reaction rates of $\mathrm{FOO}+\mathrm{NO}$ reaction, there is need to perform kinetic RRKM calculations.
3.2. Kinetic Calculations. Rate constants and branching ratios of various reaction channels in a temperature range 200$293 \mathrm{~K}$ and pressure range 1-7600 Torr were calculated on the basis of the PES obtained above via the MultiWell 2011 program [18, 19]. Kinetic bottleneck was identified using variational transition state theory (VTST) $[20,21]$ for the barrier-free entrance association processes. Therefore, we carried out restricted optimization calculation by fixing the length of $\mathrm{N}-\mathrm{O}$ bond in IM1 $\mathrm{FOONO}_{\text {tp }}$ at the multiple reference states $\operatorname{CASSCF}(8,6) /$ aug-cc-pvdz level of theory. Total single-point energy along the reaction coordinates was corrected by using CASPT2 $(8,6) /$ aug-cc-pvdz method. CASPT2//CASSCF computation was accomplished by MOLPRO 2006 program $[22,23]$. In the kinetic simulations, other necessary potential energy surface information was obtained at the $\operatorname{CCSD}(\mathrm{T}) / 6-311+\mathrm{G}(2 \mathrm{df}) / / \mathrm{MP} 2 / 6-311+\mathrm{G}(2 \mathrm{df})$ levels of theory. The total reaction rate constant $\left(k_{\text {tot }}\right)$ is the sum of rate constants of corresponding reaction channels. The total reaction rate constant $\left(k_{\text {tot }}\right)$ at various pressures of 1,10 , $100,300,760$, and 7600 Torr in a temperature range of 200$298 \mathrm{~K}$ is presented in Figure 3. It is seen that $k_{\text {tot }}$ increases with the increase of temperature in all considered pressure range, while it showed no obvious pressure dependence. The total reaction rate constant $\left(k_{\text {tot }}\right)$ obtained by experimental data and the theoretical calculations is listed in Table 1, respectively. Table 1 shows that the RRKM calculation results agree well with the experimental values of Sehested et al. [5] and $\mathrm{Li}$ et al. [8] within the studied temperature range.

Branching ratios of various reaction channels at $298 \mathrm{~K}$ in a pressure range from 1 Torr to 7600 Torr are shown in Figure 4 . One can see that, at $298 \mathrm{~K}$, the fragmentation making bimolecular products is dominant at low pressures below 17 Torr with negative pressure dependence. The dominant product is $\mathrm{P}_{1}$ FNO $+{ }^{1} \mathrm{O}_{2}$ with the yield changing from $\approx 0.93$ at 1 Torr to $\approx 0.01$ at 7600 Torr. With increasing pressure ( $>17$ Torr), the effective stabilization becomes more important and begins to take over gradually. The yield of IM2 
TABLE 1: Summary of the total reaction rate constant $\left(k_{\text {tot }}\right)$ for the reaction of FOO with NO obtained by experimental data and the theoretical calculations.

\begin{tabular}{|c|c|c|c|c|c|}
\hline$T(\mathrm{~K}) / k_{\text {tot }}\left(\times 10^{-13} \mathrm{~cm}^{3}\right.$ molecule $\left.\mathrm{s}^{-1}\right)$ & 190 & 220 & 240 & 270 & 298 \\
\hline Experimental data & $2.1 \pm 1.3^{\mathrm{b}}$ & $3.2 \pm 1.5^{\mathrm{b}}$ & $4.1 \pm 1.6^{b}$ & $5.2 \pm 1.8^{\mathrm{b}}$ & $\begin{array}{c}8.5 \pm 1.3^{\mathrm{b}} \\
14.7 \pm 0.8^{\mathrm{a}}\end{array}$ \\
\hline Theoretical calculation results (RRKM) & 3.6 & 4.4 & 5.8 & 7.3 & 12.1 \\
\hline
\end{tabular}

a represents [5]; b represents [8].

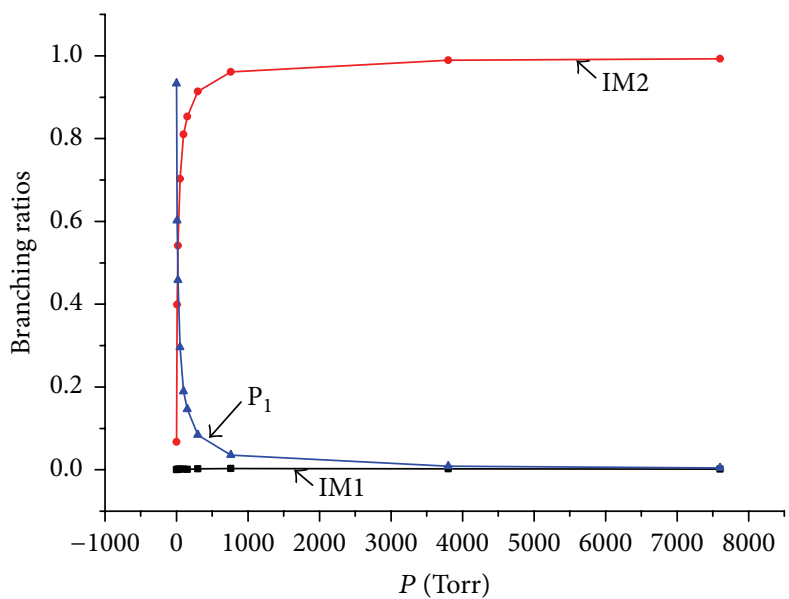

FIGURE 4: Branching ratios of various reaction channels at $298 \mathrm{~K}$ in a pressure range from 1 Torr to 7600 Torr.

$\mathrm{FOONO}_{\mathrm{cp}}$ rapidly increases with the increasing pressure and reaches a maximum of 0.99 at 7600 Torr. The stabilization effect of intermediate IM1 can be neglected because the yield of IM1 is always less than 0.005. In experiment, FNO is the major product at $298 \mathrm{~K}$ and 1 Torr, which is in agreement with our theoretical results, while IM2 $\mathrm{FOONO}_{\mathrm{cp}}$ becomes the major product when pressure changes from 17 to 7600 Torr at this temperature in our kinetic calculations. However, no associated experimental data is reported yet.

\section{Conclusions}

Detailed singlet PES of the $\mathrm{FOO}+\mathrm{NO}$ reaction have been investigated at the MP2/6-311+G(2df) and $\operatorname{CCSD}(T) / 6-$ $311+\mathrm{G}(2 \mathrm{df})$ (single-point) levels. The initial association ways are the barrierless $\mathrm{N}$-attack of $\mathrm{NO}$ at the end-O atom of FOO leading to low-lying intermediate IM1 $\mathrm{FOONO}_{\mathrm{tp}}$, and IM1 could transform into its cis-isomer IM2 FOONO ${ }_{\mathrm{cp}}$. Starting from IM1 and IM2, $\mathrm{P}_{1}$ FNO $+{ }^{1} \mathrm{O}_{2}$ is the only one feasible dissociation product. According to the further kinetic calculation, $k_{\text {tot }}$ has positive temperature dependence in the whole considered pressures. At room temperature $298 \mathrm{~K}, \mathrm{P}_{1}$ is the major product (yield $\approx 0.93$ ) at low pressure. The collision stabilization effect of intermediate plays an important role and IM2 is the major product when pressure exceeds 17 Torr and the branching ratio $\approx 0.99$ at 7600 Torr.

\section{Conflict of Interests}

The authors declare that there is no conflict of interests regarding the publication of this paper.

\section{Acknowledgments}

This work was supported by the National Natural Science Foundation of China (Grant nos. 21363013, 11564031, 11364027, and 21564011) and Inner Mongolia University of Science \& Technology Innovation Fund (2014QNGG09).

\section{References}

[1] I. V. Nikitin, "Oxygen compounds of halogens X2O2 (X is a halogen atom)," Russian Chemical Reviews, vol. 71, no. 2, pp. 8597, 2002.

[2] P. Pagsberg, E. Ratajczak, A. Sillesen, and J. T. Jodkowski, "Spectrokinetic studies of the gas-phase equilibrium $\mathrm{F}+\mathrm{O}_{2} \rightleftharpoons \mathrm{FO}_{2}$ between 295 and 359 K," Chemical Physics Letters, vol. 141, no. 1-2, pp. 88-94, 1987.

[3] Z. G. Wei, Q. S. Li, S. W. Zhang, Y. B. Sun, and C. C. Sun, "Quantum mechanical studies on the potential energy surface of the reactions $3 \mathrm{NCN} / 3 \mathrm{CNN}+\mathrm{NO},{ }^{1} \mathrm{NNO}+\mathrm{CN}$ and ${ }^{2} \mathrm{~N}_{3}+\mathrm{CO}$," Journal of Molecular Structure: THEOCHEM, vol. 722, no. 1-3, pp. 139-146, 2005.

[4] L. Jin, Y.-H. Ding, J. Wang, and C.-C. Sun, "Reaction mechanism of the CCN radical with nitric oxide," Journal of Computational Chemistry, vol. 27, no. 7, pp. 883-893, 2006.

[5] J. Sehested, K. Sehested, O. J. Nielsen, and T. J. Wallington, "Atmospheric chemistry of $\mathrm{FO}_{2}$ radicals: reaction with $\mathrm{Ch}_{4}, \mathrm{O}_{3}$, $\mathrm{No}, \mathrm{No}_{2}$, and Co at $295 \mathrm{~K}$," Journal of Physical Chemistry, vol. 98, no. 27, pp. 6731-6739, 1994.

[6] J. S. Francisco, "An $a b$ initio investigation of the significance of the HOOF intermediate in coupling reactions involving $\mathrm{FOO}_{x}$ and $\mathrm{HO}_{x}$ species," The Journal of Chemical Physics, vol. 98, no. 3, article 2198, 1993. 
[7] J. S. Franciso and Y. Su, "An ab initio study of the reaction between FO radicals and $\mathrm{H}_{2} \mathrm{O}$," Chemical Physics Letters, vol. 215, no. 1-3, pp. 58-62, 1993.

[8] Z. Li, R. R. Friedl, and S. P. Sander, "Kinetics of $\mathrm{FO}_{2}$ with NO, $\mathrm{NO}_{2}, \mathrm{O}_{3}, \mathrm{CH}_{4}$, and $\mathrm{C}_{2} \mathrm{H}_{6}$," Journal of Physical Chemistry, vol. 99, no. 36, pp. 13445-13451, 1995.

[9] T. S. Dibble and J. S. Francisco, "Structure, vibrational frequencies, and stability of a reactive intermediate: FOONO," Journal of the American Chemical Society, vol. 119, no. 12, pp. 2894-2895, 1997.

[10] Y. Sun, J. Yao, M. Sun, H. Zhang, and M. Zhang, "Theoretical mechanistic study on the reactions between $\mathrm{FO}_{2}+\mathrm{NO}$ and $\mathrm{FO}$ $+\mathrm{NO}_{2}$," Journal of Molecular Structure: THEOCHEM, vol. 916, no. 1-3, pp. 10-16, 2009.

[11] K. A. Holbrook, M. J. Pilling, and S. H. Robertson, Unimolecular Reactions, Wiley, Chichester, UK, 1996.

[12] W. J. Hehre, L. Radom, P. V. R. Schleyer et al., Ab Initio Molecular Orbital Theory, John Wiley \& Sons, New York, NY, USA, 1986.

[13] K. Fukui, "The path of chemical reactions-the IRC approach," Accounts of Chemical Research, vol. 14, no. 12, pp. 363-368, 1981.

[14] M. Page and J. W. McIver Jr., "On evaluating the reaction path Hamiltonian," The Journal of Chemical Physics, vol. 88, no. 2, pp. 922-935, 1988.

[15] C. Gonzalez and H. B. Schlegel, "An improved algorithm for reaction path following," The Journal of Chemical Physics, vol. 90, no. 4, pp. 2154-2161, 1989.

[16] C. Gonzalez and H. B. Schlegel, "Reaction path following in mass-weighted internal coordinates," Journal of Physical Chemistry, vol. 94, no. 14, pp. 5523-5527, 1990.

[17] M. J. Frisch, G. W. Truck, H. B. Schlegel et al., GAUSSIAN 03, Revision A.1, Guassian, Inc, Pittsburgh, Pa, USA, 2003.

[18] J. R. Barker, "Multiple-well, multiple-path unimolecular reaction systems. I. MultiWell computer program suite," International Journal of Chemical Kinetics, vol. 33, no. 4, pp. 232-245, 2001.

[19] J. R. Barker, N. F. Ortiz, J. M. Preses et al., MultiWell-2.08 Software, University of Michigan, Ann Arbor, Mich, USA, 2007, http://aoss.engin.umich.edu/multiwell/.

[20] S. J. Klippenstein, "An efficient procedure for evaluating the number of available states within a variably defined reaction coordinate framework," The Journal of Physical Chemistry, vol. 98, no. 44, pp. 11459-11464, 1994.

[21] S. J. Klippenstein, "A bond length reaction coordinate for unimolecular reactions. II. Microcanonical and canonical implementations with application to the dissociation of NCNO," The Journal of Chemical Physics, vol. 94, article 6469, 1991.

[22] H.-J. Werner and P. J. Knowles, "A second order multiconfiguration SCF procedure with optimum convergence," The Journal of Chemical Physics, vol. 82, no. 11, pp. 5053-5063, 1985.

[23] H.-J. Werner, P. J. Knowles, G. Knizia et al., 2006 MOLPRO, version 2006.1, A package of ab initio programs, http://www.molpro.net. 

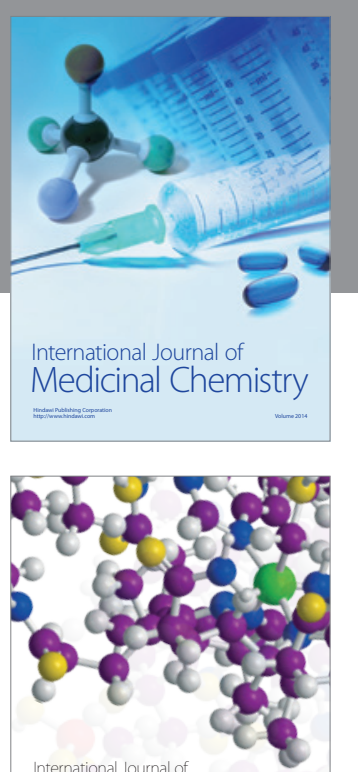

Carbohydrate Chemistry

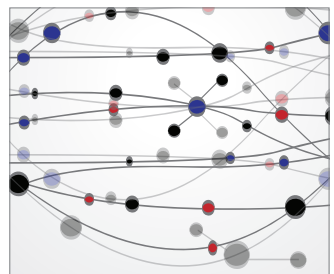

The Scientific World Journal
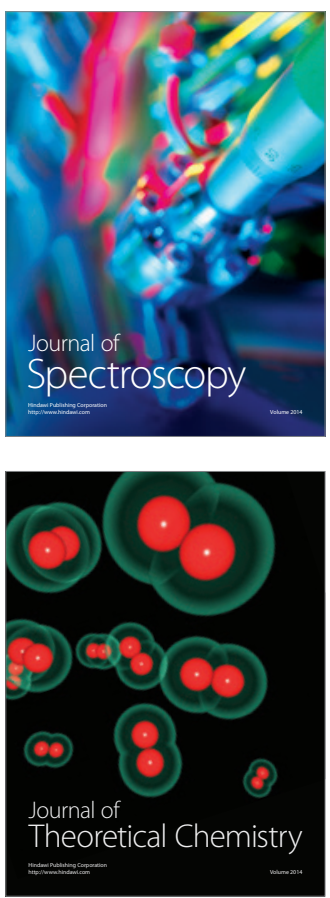
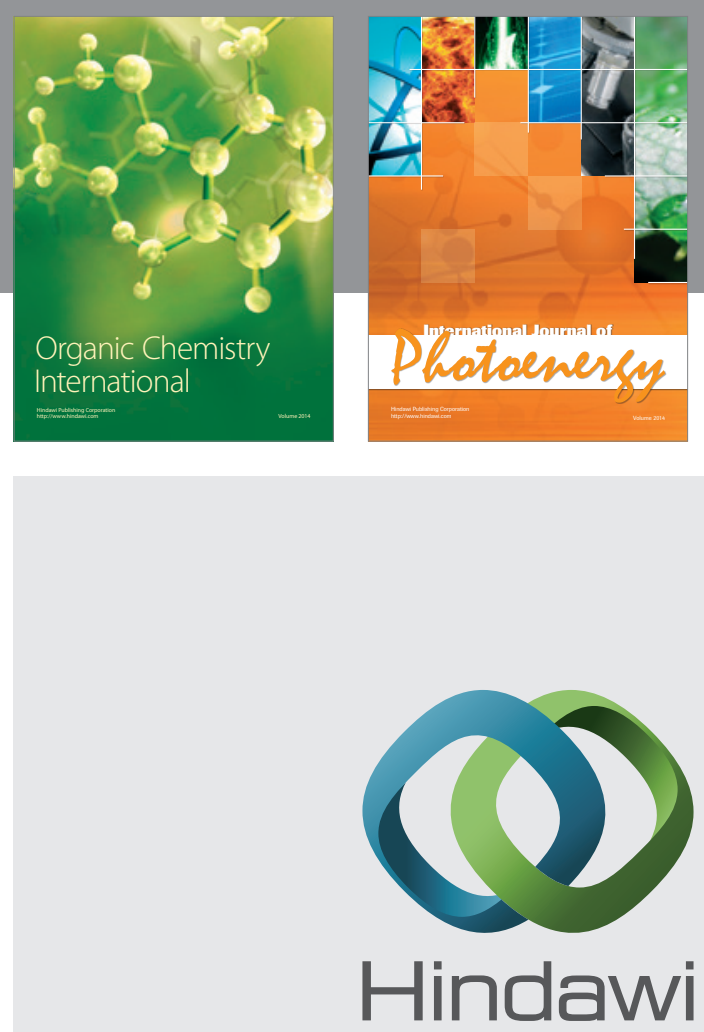

Submit your manuscripts at

http://www.hindawi.com

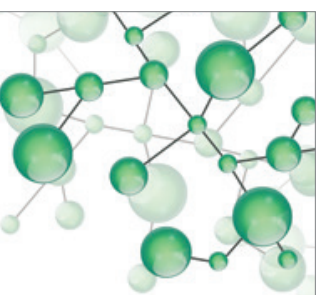

International Journal of

Inorganic Chemistry

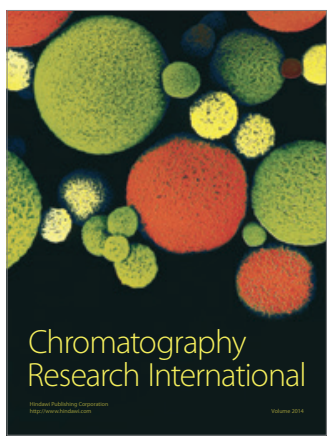

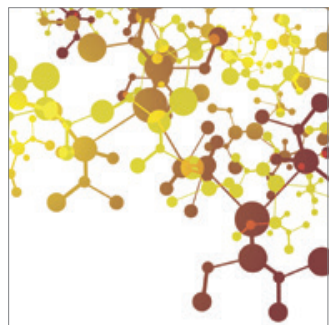

Applied Chemistry
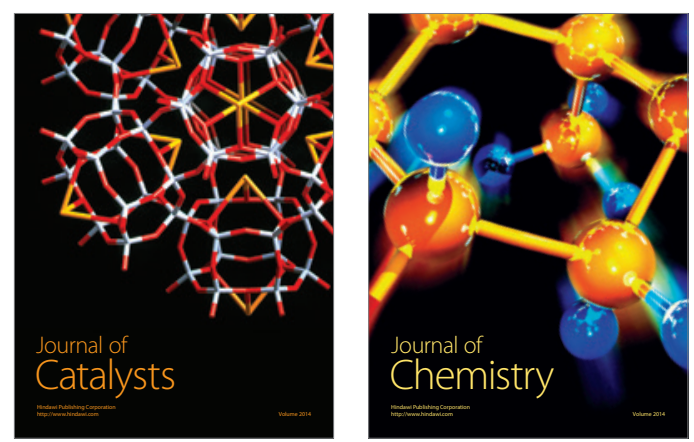
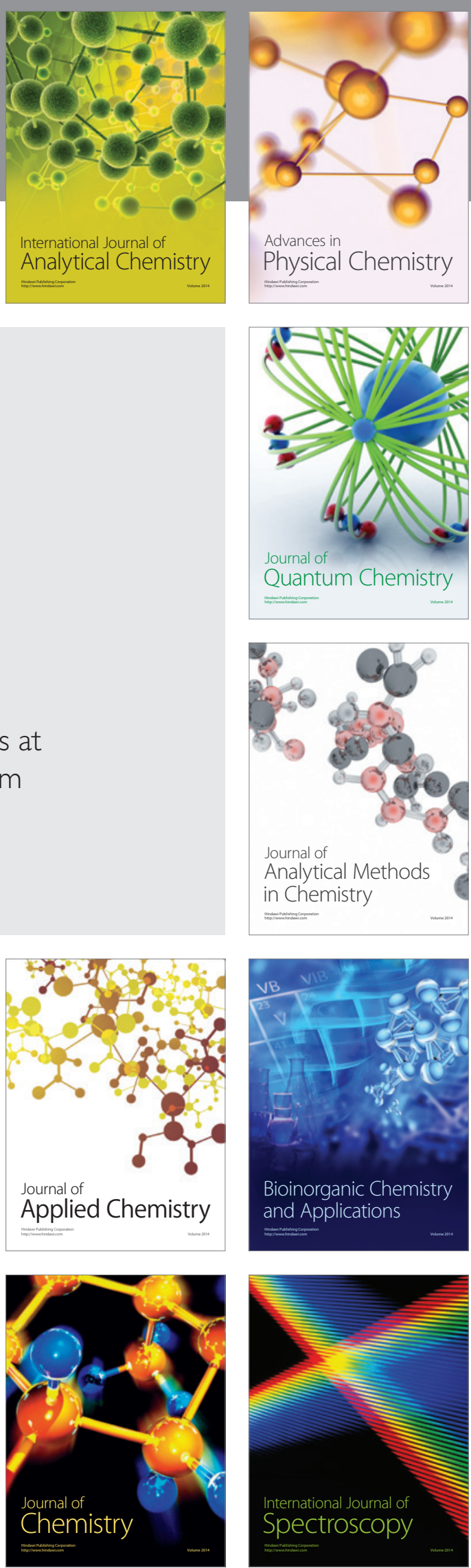